\title{
Diferentes Densidades de Plantas Daninhas e Métodos de Controle nos Componentes de ProduÇÃo do Milho ORGÂnico ${ }^{1}$
}

\author{
Different Weed Densities and Control Methods of Organic Corn Production Components
}

\author{
CHIOVATO, M.G. ${ }^{2}$, GALVÃO, J.C.C. ${ }^{3}$, FONTANÉTTI, A. ${ }^{4}$, FERREIRA, L.R..$^{3}$, MIRANDA, G.V. ${ }^{3}$, \\ RODRIGUES, O.L. ${ }^{4}$. e BORBA, A.N. ${ }^{2}$
}

\begin{abstract}
RESUMO - O objetivo deste trabalho foi verificar a eficiência de métodos de controle mecânico e diferentes densidades populacionais de picão-preto (Bidens pilosa), capim-braquiária (Brachiaria decumbens) e capim-marmelada (Brachiaria plantaginea) e suas interferências nos componentes de produção do milho, visando o manejo orgânico. O experimento foi instalado em casa de vegetação, no delineamento inteiramente casualizado, com três repetições, no esquema fatorial $3 \times 3+1$. O primeiro fator foi constituído por três densidades de plantas daninhas (duas, quatro e seis plantas por vaso) e, o segundo, pelos manejos: roçada das plantas daninhas nos estádios de quatro e oito folhas do milho; capina das plantas daninhas no estádio de quatro folhas do milho; milho sem controle das plantas daninhas; e o tratamento adicional milho cultivado sem as plantas daninhas (testemunha). O cultivar de milho utilizado foi o UFVM 100, semeado simultaneamente com as plantas daninhas em vasos contendo $18 \mathrm{~L}$ de substrato (solo + composto orgânico). Para a espécie Bidens pilosa, a roçada e o tratamento sem controle foram os que mais interferiram na produção de matéria seca (MS) das folhas do milho. Em se tratando das variáveis MS das folhas, dos colmos e dos órgãos reprodutivos do milho, não houve diferenças significativas entre a capina e o tratamento em que o milho foi cultivado sem a planta daninha, indicando que a roçada não proporcionou controle eficiente da espécie Bidens pilosa no cultivo do milho orgânico. Quanto a B. plantaginea, a roçada e a capina proporcionaram o mesmo acúmulo de MS quando o milho conviveu com duas plantas da espécie daninha, porém nas maiores densidades, quatro e seis plantas por vaso, o tratamento com roçada foi semelhante ao sem controle, demonstrando que a roçada é eficiente no controle de $B$. plantaginea apenas quando esta se encontra em baixa densidade populacional. Para $B$. decumbens, a densidade de seis plantas por vaso foi a que proporcionou maior redução de MS das folhas do milho, independentemente do manejo.
\end{abstract}

Palavras-chave: capina, milho orgânico, planta daninha, roçagem.

ABSTRACT - The objective of this work was to verify the efficiency of mechanic control methods and different populational densities of Bidens pilosa, Brachiaria decumbens and Brachiaria plantaginea and their interference in corn production components, for organic management purposes. The experiment was conducted in a green house, in a completely randomized design, with three replicates, in a factorial scheme $3 \times 3+1$. The first trial was composed by three weed densities and the second by the treatments (weed cutting at four and eight developed leaf stages, handweeding at four developed leaf stage, corn without weed control, and an additional treatment, corn without weed (control). The corn cultivar UFVM 100 was sowed simultaneously with the weeds in $18 \mathrm{~L}$ pots filled with substrate (soil + organic matter). For Bidens pilosa, the greatest interference in leaf dry matter was observed in the cutting and without weed control treatments. When corn was cultivated without weeds and hand-weeded, no significant differences were observed in leaf dry matter, stem and reproductive organs, indicating that cutting was not efficient at controlling Bidens pilosa under organic corn crop conditions. When corn was planted together with

Recebido para publicação em 14.9.2006 e na forma revisada em 15.5.2007.

Estudante de Agronomia do Dep. de Fitotecnia da Universidade Federal de Viçosa, 36570-000 Viçosa-MG, $<$ marcellgch@yahoo.com.br>; ${ }^{3}$ Professor Associado do Dep. de Fitotecnia da Universidade Federal de Viçosa, 36570-000 Viçosa. ${ }^{4}$ Doutorando do Dep. de Fitotecnia da Universidade Federal de Viçosa, 36570-000 Viçosa-MG. 


\begin{abstract}
B. plantaginea plants, cutting and hand-weeding provided the same dry matter accumulation; however, at higher densities (four and six plants/vase), the cutting and corn without weed control treatments were similar showing that cutting is efficient in controlling B. plantaginea at a low population density. B. decumbens showed the highest leaf dry matter reduction at a six plant/ vase density, regardless of the type of treatment.
\end{abstract}

Keywords: cutting, organic corn, weed, hand weeding.

\section{INTRODUÇÃO}

A produção orgânica de milho em sistema de plantio direto tem como principal desafio o manejo das plantas daninhas, principalmente no período de conversão das lavouras convencionais. Nesse sistema, o método químico é substituído, na maior parte das vezes, por métodos culturais e mecânicos (Darolt \& Skora Neto, 2002). Os herbicidas dessecantes são substituídos por plantas de cobertura que apresentam crescimento inicial rápido e grande produção de biomassa, com capacidade de sombreamento das plantas daninhas; para substituição dos herbicidas durante o ciclo da cultura utiliza-se a roçada, aliada a outras práticas culturais de manejo (Darolt \& Skora Neto, 2002).

No entanto, a eficiência da roçada depende, em grande parte, das espécies de plantas daninhas, da freqüência do corte e do estádio de desenvolvimento das plantas (Deuber, 1992). A utilização exclusiva da roçada no sistema de plantio direto orgânico tem levado ao estabelecimento de espécies de plantas daninhas que apresentam rebrota, dificultando o manejo (Melo, 2004). Este autor verificou maior produção de biomassa total de plantas daninhas no sistema de plantio direto orgânico, em comparação ao sistema de plantio direto tradicional com utilização de herbicidas, devido principalmente à alta capacidade de rebrota de algumas espécies invasoras, como Bidens pilosa. De acordo com Heringer (2002), as roçadas devem coincidir com o florescimento das espécies daninhas, quando as reservas destas são deslocadas para a produção de sementes, reduzindo a possibilidade de rebrota. No entanto, tal prática pode ser inviabilizada em razão do período crítico de matocompetição entre infestantes e a planta de milho.

A constante remoção da área foliar pela roçada minimiza a competição por luz (Cook
$\&$ Ratcliff, 1994). No entanto, não se pode afirmar que esse efeito interfira de maneira proporcional no desenvolvimento das raízes, diminuindo também a competição por água e nutrientes, abaixo do solo, porque a absorção de nutrientes e a eficiência na utilização destes são estratégias de competição que variam entre as espécies daninhas. Bidens pilosa, por exemplo, apresenta elevada eficiência na utilização do nitrogênio absorvido, convertendo-o rapidamente em biomassa (Procópio et al., 2004).

A redução do rendimento de grãos de milho devido à competição estabelecida com as plantas daninhas varia em função da espécie invasora, do grau de infestação, das condições edafoclimáticas e do estádio fenológico da cultura (Kozlowski, 2002). Manejar esses fatores de forma que se minimize a competição entre as plantas daninhas e a cultura pelos recursos é fundamental para a produção orgânica de milho em sistema de plantio direto. Nesse sentido, os métodos empregados ou suas combinações deverão reduzir as populações de plantas daninhas e evitar que a competição se estabeleça durante o período crítico de interferência, no qual a produtividade da cultura é afetada. Assim, é necessário avaliar as formas de manejo indicadas para cada espécie e para o grau de infestação, de modo que o período crítico de prevenção da interferência, na cultura do milho, corresponda ao período compreendido entre os estádios fenológicos de duas a oito folhas totalmente expandidas (Kozlowski, 2002).

Objetivou-se, neste trabalho, avaliar a interferência de diferentes densidades populacionais e métodos de controle das espécies Bidens pilosa, Brachiaria decumbens e Brachiaria plantaginea, submetidas à capina e à roçagem, no crescimento e desenvolvimento das plantas de milho, visando definir manejos para o sistema de plantio direto orgânico. 


\section{MATERIAL E MÉTODOS}

O trabalho foi realizado no período de outubro de 2004 a fevereiro de 2005 em casa de vegetação, no Departamento de Fitotecnia da Universidade Federal de Viçosa, em ViçosaMG.

Foram avaliadas três espécies de plantas daninhas: picão-preto (Bidens pilosa), capimbraquiária (Brachiaria decumbens) e capimmarmelada (Brachiaria plantaginea), cada espécie em um experimento, no delineamento inteiramente casualizado, com três repetições, em esquema fatorial $3 \times 3+1$. O primeiro fator foi constituído por três densidades de plantas daninhas (duas, quatro e seis plantas por vaso) e o segundo, por três manejos dessas plantas (capina no estádio de quatro folhas do milho, roçada no estádio de quatro e oito folhas do milho e milho sem controle das plantas daninhas). O tratamento adicional (testemunha) consistiu no cultivo do milho livre da interferência das plantas daninhas.

Utilizaram-se vasos plásticos com capacidade volumétrica de $18 \mathrm{~L}$ e altura de $40 \mathrm{~cm}$. O solo foi classificado como Latossolo VermelhoAmarelo (LVa), e suas características químicas estão apresentadas na Tabela 1.

Ao solo seco, destorroado e passado em peneira foi adicionada dose equivalente a $40 \mathrm{~m}^{3} \mathrm{ha}^{-1}$ de composto orgânico, utilizado em experimento de campo (Melo, 2004), e
$0,035 \mathrm{~kg}$ vaso $^{-1}$ de $\mathrm{P}_{2} \mathrm{O}_{5}$ na forma de termofosfato magnesiano. As características químicas do composto orgânico estão apresentadas na Tabela 2 .

Foi utilizada a variedade de milho de polinização aberta UFVM 100, mantendo-se uma planta por vaso. Simultaneamente ao milho foram semeadas as espécies de plantas daninhas; após a emergência destas, realizou-se o desbaste, mantendo-se as densidades almejadas. As irrigações foram feitas diariamente por aspersão, a fim de manter a umidade do solo próximo à capacidade de campo.

O período de interferência - no mesmo vaso, entre a planta de milho e as espécies daninhas - foi considerado aquele compreendido entre a emergência das plantas daninhas e o encerramento do experimento, realizado no florescimento das plantas de milho.

A roçagem foi feita cortando-se as plantas daninhas à altura de 5,0 cm do solo, com uma tesoura, nos estádios de quatro e oito folhas completamente expandidas do milho. A capina consistiu na retirada total das plantas daninhas, no estádio de quatro folhas do milho.

No florescimento do milho, na liberação do pendão e do estilo-estigma avaliaram-se a altura das plantas de milho, do solo até a inserção da folha-bandeira, e o diâmetro de colmo, utilizando-se um paquímetro, pela parte mais larga do colmo, a $10 \mathrm{~cm}$ do solo. Finda

Tabela 1 - Características químicas do solo LVa

\begin{tabular}{|c|c|c|c|c|c|c|c|c|c|c|}
\hline $\mathrm{pH}$ & $\mathrm{P}$ & $\mathrm{K}$ & $\mathrm{Ca}$ & $\mathrm{Mg}$ & $\mathrm{Al}$ & $\mathrm{H}+\mathrm{Al}$ & SB & $\mathrm{CTC}(\mathrm{t})$ & $\mathrm{CTC}(\mathrm{T})$ & $\mathrm{V}$ \\
\hline & \multicolumn{2}{|c|}{$---\mathrm{mg} \mathrm{dm}^{-3}$} & \multicolumn{7}{|c|}{---- } & $\%$ \\
\hline 5,8 & 1,9 & 73 & 3,3 & 1,1 & 0 & 3,63 & 4,59 & 4,59 & 8,22 & 56 \\
\hline
\end{tabular}

As determinações químicas foram efetuadas conforme Embrapa (1997); pH em água na proporção de 1: 2,5 para solo: água; Ca, Mg e $\mathrm{Al}=$ extrator $\mathrm{KCl} 1 \mathrm{~N} ; \mathrm{P}$ e $\mathrm{K}=$ extrator Mehlich 1; e acidez extraível $\mathrm{H}+\mathrm{Al}=$ extrator SMP.

Tabela 2 - Características químicas do composto orgânico com base no peso seco

\begin{tabular}{|c|c|c|c|c|c|c|c|c|c|c|}
\hline $\mathrm{N}$ & $\mathrm{P}$ & $\mathrm{K}$ & $\mathrm{Ca}$ & $\mathrm{Mg}$ & $\mathrm{S}$ & $\mathrm{B}$ & $\mathrm{Cu}$ & $\mathrm{Fe}$ & $\mathrm{Mn}$ & $\mathrm{Zn}$ \\
\hline \multicolumn{6}{|c|}{ 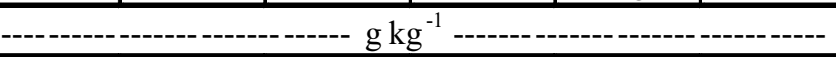 } & \multicolumn{5}{|c|}{ - } \\
\hline 16,6 & 4,19 & 2,62 & 9,56 & 3,68 & 2,11 & 10,75 & 35,62 & 37242,6 & 274,73 & 71,9 \\
\hline
\end{tabular}

As determinações foram efetuadas de acordo com o método descrito por Kiehl (1985) e umidade de 13\%. 
essa etapa, retirou-se a parte aérea das plantas de milho, separando-as em folhas, órgãos reprodutivos (primórdio de espiga e pendão) e colmo. O material foi levado à estufa de circulação forçada de ar, a $70{ }^{\circ} \mathrm{C}$, até atingir peso constante, para determinação da matéria seca.

Os dados foram submetidos à análise de variância e de regressão, de acordo com a natureza das características estudadas (qualitativas ou quantitativas), sendo as médias comparadas pelo teste de Tukey a $5 \%$ de probabilidade. Na comparação dos métodos de manejo com a testemunha foram utilizados contrastes entre as médias, e a significância foi estabelecida de acordo com o teste $\mathrm{F}$ a $5 \%$ de probabilidade.

\section{RESULTADOS E DISCUSSÃO}

Para Bidens pilosa, não se verificou efeito dos métodos de manejo e da densidade de plantas nas variáveis diâmetro de colmo e altura das plantas de milho. No entanto, houve efeito isolado dos métodos de manejo no acúmulo de matéria seca (MS) das folhas, MS dos órgãos reprodutivos e MS do colmo das plantas de milho. De acordo com a Tabela 3, verificou-se que a capina proporcionou, de modo geral, maior acúmulo de matéria seca das plantas, independentemente das densidades de Bidens pilosa. Observou-se ainda que as duas roçadas efetuadas nos estádios de quatro e oito folhas do milho não foram suficientes para evitar a interferência da espécie daninha no desenvolvimento das plantas de milho, reduzindo sua produção de matéria seca (Tabela 3 ).

Essa espécie é extremamente eficiente na absorção e utilização do nitrogênio, conver- tendo-o rapidamente em biomassa (Procópio et al., 2004). O rápido acúmulo de biomassa aumenta a demanda dos demais nutrientes, estimulando a absorção pelas raízes. No caso da roçagem, apenas a parte aérea das plantas daninhas é eliminada, minimizando a competição por luz. No entanto, esse efeito não elimina a competição abaixo do solo, pois as plantas conseguem utilizar as reservas acumuladas e emitir novas brotações, o que provavelmente explica o menor acúmulo de matéria seca das plantas de milho no tratamento com a roçada.

O acúmulo de matéria seca pelas plantas de milho no tratamento com capina, independentemente da densidade de $B$. pilosa, não diferiu daquele da testemunha, na qual o milho foi cultivado sem a presença da planta daninha (Tabela 4). Dos fatores que influenciam o grau de interferência das plantas daninhas sobre as culturas, o mais importante é o período em que as infestantes e as plantas cultivadas estão disputando os recursos do meio (Pitelli, 1985). De acordo com Silva et al. (2004), o período crítico de competição para a cultura do milho vai dos 20 aos 60 dias após a emergência, ou seja, do estádio de 3 a 14 folhas completamente expandidas. Assim, a capina realizada no estádio de quatro folhas do milho evitou que as plantas de Bidens pilosa interferissem na produção de matéria seca, por evitar a competição durante o período crítico da cultura.

Quanto a Brachiaria plantaginea, houve interação significativa entre as densidades de plantas x manejos apenas para MS de colmo das plantas de milho. Na densidade de duas plantas por vaso, a capina e a roçada proporcionaram produções iguais de MS de colmo (Tabela 5). No entanto, na densidade de seis plantas, os manejos, capina e roçada, não

Tabela 3 - Interferência de Bidens pilosa submetido a capina e roçada sobre a produção de matéria seca (MS) das plantas de milho - UFV

\begin{tabular}{|c|c|c|c|}
\hline Manejos & MS folha & MS org. repr. & MS colmo \\
\hline & ------- & $----g$ & ----------- ------ ------- \\
\hline Capina & $24,60 \mathrm{a}^{\mathrm{I}^{\prime}}$ & $5,94 \mathrm{a}$ & $76,54 \mathrm{a}$ \\
\hline Roçada & $17,93 \mathrm{~b}$ & $3,04 \mathrm{ab}$ & $48,11 \mathrm{~b}$ \\
\hline Sem controle & $18,18 \mathrm{~b}$ & $2,74 \mathrm{~b}$ & $46,14 \mathrm{~b}$ \\
\hline $\mathrm{CV} \%$ & 19,95 & 68,26 & 53,68 \\
\hline
\end{tabular}

${ }^{1}$ Médias seguidas pela mesma letra na coluna não diferem entre si pelo teste de Tukey a 5\% de probabilidade. 
Tabela 4 - Estimativa dos contrastes entre os métodos de manejo e a testemunha (milho cultivado sem as plantas daninhas) UFV

\begin{tabular}{|l|c|c|c|c|c|}
\hline \multirow{2}{*}{\multicolumn{1}{|c|}{ Contra stes }} & Bidens pilosa & \multicolumn{3}{|c|}{ B. plantaginea } & B. decumbens \\
\cline { 2 - 6 } & $\begin{array}{c}\text { MS folhas } \\
(\mathrm{g})\end{array}$ & $\begin{array}{c}\text { MS folhas } \\
(\mathrm{g})\end{array}$ & $\begin{array}{c}\text { MS colmo } \\
(\mathrm{g})\end{array}$ & $\begin{array}{c}\text { Diâm. colmo } \\
(\mathrm{cm})\end{array}$ & $\begin{array}{c}\text { MS folhas } \\
(\mathrm{g})\end{array}$ \\
\hline Capina vs testemunha & $-4,40^{\mathrm{ns}}$ & $-2,42^{\mathrm{ns}}$ & $-14,18^{\mathrm{ns}}$ & $-0,56^{\mathrm{ns}}$ & $-9,11^{\mathrm{ns}}$ \\
\hline Roçada vs testemhuna & $-11,06^{*}$ & $-11,21^{*}$ & $-50,13^{*}$ & $-2,89^{*}$ & $-7,23^{\mathrm{ns}}$ \\
\hline S. controle vs testemunha & $-10,82^{*}$ & $-11,91 *$ & $-69,40 *$ & $-2,73^{*}$ & $-10,41^{\mathrm{ns}}$ \\
\hline
\end{tabular}

* significativo pelo teste $\mathrm{F}$ a $5 \%$ de probabilidade.

Tabela 5 - Média dos valores de matéria seca (MS) do colmo do milho obtidos nos três métodos de manejo, em diferentes densidades de Brachiaria plantaginea, em sistema orgânico - UFV

\begin{tabular}{|l|c|c|c|}
\hline \multirow{2}{*}{ Manejo } & \multicolumn{3}{|c|}{ MS colmo (g) } \\
\cline { 2 - 4 } & 2 & 4 & 6 \\
\hline Capina & $96,07 \mathrm{aA}$ & $112,80 \mathrm{aA}$ & $46,06 \mathrm{aB}$ \\
Roçada & $74,06 \mathrm{aA}$ & $39,17 \mathrm{bA}$ & $33,86 \mathrm{aA}$ \\
Sem controle & $34,36 \mathrm{bA}$ & $20,30 \mathrm{bA}$ & $34,63 \mathrm{aA}$ \\
\hline
\end{tabular}

As médias seguidas pela mesma letra maiúscula na coluna e minúscula na linha não diferem significativamente a $5 \%$ de probabili dade pelo teste de Tukey.

diferiram do tratamento sem controle, indicando que a interferência das plantas de $B$. plantaginea sobre as plantas de milho está associada com a densidade populacional da espécie. Esse fato também foi observado para MS foliar (Figura 1) e diâmetro de colmo (Figura 2), os quais reduziram proporcionalmente com o aumento da densidade de plantas de B. plantaginea, independentemente dos métodos de manejo.

Comparando os métodos de manejo de B. plantaginea com os da testemunha (milho cultivado sem as espécies daninhas), verificouse que apenas a capina não diferiu da testemunha, ou seja, a roçada e o tratamento sem controle reduziram o rendimento de matéria seca e o diâmetro de colmo do milho (Tabela 4).

Para Brachiaria decumbens, houve efeito significativo da densidade de plantas, independentemente do sistema de manejo, apenas para a MS de folhas de milho. A densidade de seis plantas por vaso foi a que proporcionou maior redução de MS das folhas do milho (Figura 3).
Não houve diferença significativa entre os métodos de manejo - capina e roçada - em relação à testemunha para a MS de folhas do milho (Tabela 4).

As espécies do gênero Brachiaria são perenes, agressivas e resistentes, sendo consideradas importantes espécies daninhas para a maioria das culturas anuais (Jakelaitis et al., 2004). Contudo, alguns trabalhos têm demonstrado que a produtividade do milho não é alterada quando em competição com espécies de Brachiaria (Cobucci, 2001; Duarte et al., 1995). No entanto, deve-se levar em consideração que a interferência das plantas do gênero Brachiaria sobre os componentes de produção do milho varia em função das características peculiares de cada espécie.

O milho apresenta rápido crescimento inicial, tornando-se, assim, excelente competidor, principalmente com espécies de menor taxa inicial de crescimento. B. decumbens, por exemplo, é uma forrageira comumente utilizada em sistemas consorciados com o milho, para formação e recuperação de pastagens, por 


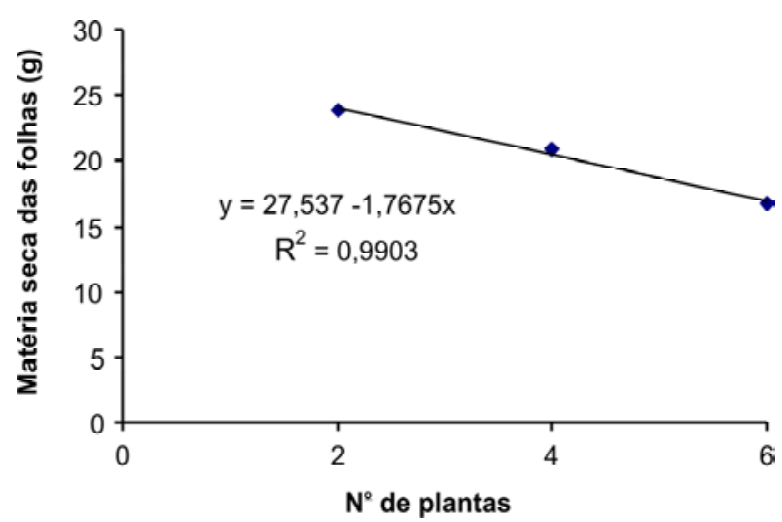

Figura 1 - Redução da matéria seca (g) das folhas de milho em função do número de plantas por vaso (densidade) de Brachiaria plantaginea-UFV.

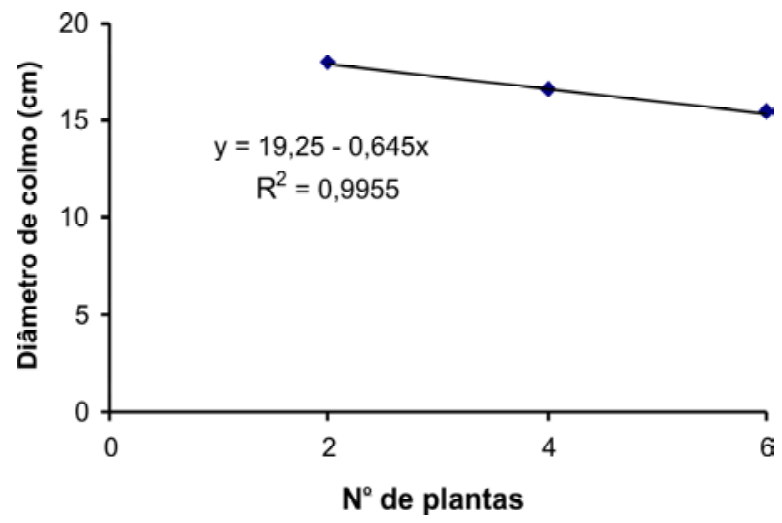

Figura 2 - Redução do diâmetro de colmo (cm) das plantas de milho em função do número de plantas por vaso (densidade) de Brachiaria plantaginea - UFV.

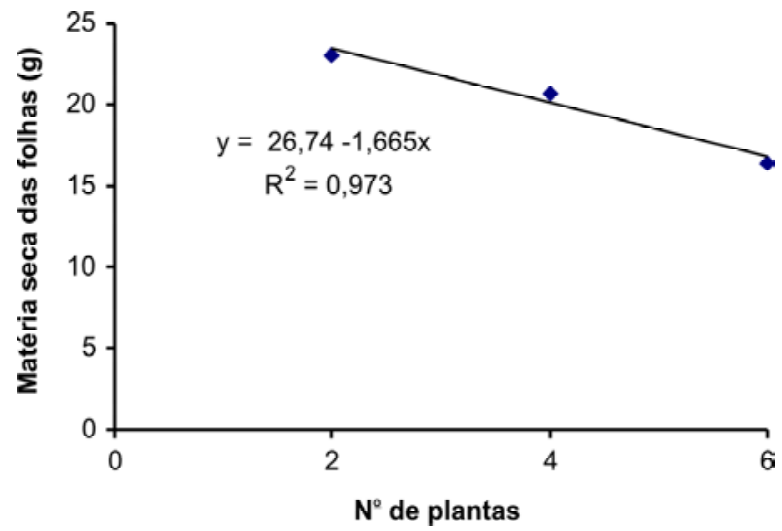

Figura 3 - Redução da matéria seca das folhas de milho em função do número de plantas por vaso (densidade) de Brachiaria decumbens - UFV. não interferir de maneira significativa na produção de grãos (Souza Neto, 1993; Jakelaitis et al., 2004). Essa espécie apresenta crescimento inicial lento, permitindo que o milho se estabeleça primeiro, sombreando a forrageira, a qual tem seu crescimento e desenvolvimento reduzido, pois, quando submetida a menor nível de radiação, não atinge o ponto de saturação luminosa, reduzindo a fotossíntese e, conseqüentemente, a produção de fotoassimilados (Castro et al., 1999).

Já B. plantaginea possui rápido crescimento inicial, porém a eficiência da planta cultivada na utilização dos recursos do meio é dependente, entre outros fatores, da época de emergência relativa às espécies daninhas; a elevada disponibilidade de recursos pode ter favorecido a cultura na relação de competição com B. plantaginea (Spader \& Vidal, 2000). O ponto crucial no incremento competitivo de uma espécie em relação à outra se deve à taxa de crescimento inicial; aquela que apresentar maior taxa de crescimento dominará a utilização dos recursos, os quais ficam indisponiveis para as espécies concorrentes (Johnson et al., 1998), evidenciando a necessidade de controle de B. plantaginea no início do desenvolvimento da cultura. Isso explica a eficiência da capina realizada no estádio de quatro folhas do milho, ou seja, antes de se estabelecer o período crítico de competição.

Outra questão a ser considerada quanto ao manejo das plantas de Brachiaria é o nível de infestação. De acordo com os resultados deste experimento, a roçada não difere do tratamento capina na densidade de duas plantas de $B$. plantaginea por vaso. No entanto, quando em maior densidade de plantas, a roçada não é eficiente para evitar ou minimizar a competição com as plantas de milho.

Os efeitos de B. plantaginea nas características agronômicas da cultura do milho são evidentes quando as medidas de controle são realizadas precocemente e ocorrer reinfestação da área com B. plantaginea após a emergência da cultura (Spader \& Vidal, 2000). O mesmo fato é observado quando se trata de B. decumbens.

Conclui-se que a interferência da espécie Bidens pilosa sobre o desenvolvimento das plantas de milho é minimizada quando se realiza 
a capina no estádio de quatro folhas completamente expandidas. A roçada não é indicada como método de controle dessa espécie. Para B. plantaginea, a roçada pode ser indicada como método de controle na cultura do milho em sistema de plantio direto orgânico, desde que a infestação dessa espécie seja baixa. A interferência de $B$. decumbens sobre o desenvolvimento das plantas de milho está relacionada diretamente com sua densidade populacional e independe do método de controle. Espécies com alta taxa de crescimento inicial e eficiência na utilização de recursos para produção de biomassa devem ser controladas com capinas realizadas no estádio de quatro folhas completamente expandidas do milho.

\section{AGRADECIMENTOS}

À FAPEMIG, pelo apoio financeiro ao projeto e ao CNPq.

\section{LITERATURA CITADA}

CASTRO, C. R. T. et al. Produção de forrageira de gramíneas cultivadas sob luminosidade reduzida. R. Bras. Zootec., v. 28, n. 5, p. 919-927, 1999.

COBUCCI, T. Manejo integrado de plantas daninhas em sistema de plantio direto. In: ZAMBOLIM, L. (Ed.). Manejo integrado fitossanidade: cultivo protegido, pivô central e plantio direto. Viçosa, MG: Universidade Federal de Viçosa, 2001. p. 583-624.

COOK, S. J.; RATCLIFF, D. A study of the effects of root and shoot competition on the growth of Green Panic (Panicum maximum var. Trichoglume) seedlings in an existing grassland using root exclusion tubes. J. Appl. Ecol., v. 21, p. 971-982, 1994.

DAROLT, M. R.; SKORA NETO, F. Sistema de plantio direto em agricultura orgânica. R. Plantio Direto, p. 28-31, 2002.

DEUBER, R. Ciência das plantas daninhas: fundamentos. Jaboticabal: FUNEP, 1992. $431 \mathrm{p}$.

DUARTE, J. M. et al. Producción de maiz ( Zea mays L.), soya (Glycine max L.) y caupi (Vigna ungiculada) sembrados en asociación con gramíneas en el trópico húmedo. Past Tropic., v. 17, n. 2, p. 12-19, 1995.
EMPRESA BRASILEIRA DE PESQUISA AGROPECUÁRIA - EMBRAPA. Centro Nacional de Pesquisa de Solos. Manual de métodos de análise de solo. Rio de Janeiro, 1997. 212 p.

HERINGER, I.; JACQUES, A. V. Á. Acumulação de forragem e material morto em pastagem nativa sob distintas alternativas de manejo em relação às queimadas. R. Bras. Zootec., v. 31, n. 2, p. 599-604, 2002.

JAKELAITIS, A. et al. Manejo de plantas daninhas no consórcio de milho com capim-braquiária (Brachiaria decumbens). Planta Daninha, v. 22, n. 4, p. 553-560, 2004.

JOHNSON, D. E.; DINGKUHN, M.; JONES, M. P. The influence of rice plant type on the effect of weed competition on Oryza sativa and Oryza glaberrima. Weed Res., v. 38, n. 3, p. 207-216, 1998.

KIEHL, E.J. Fertilizantes orgânicos. Piracicaba: Agronômica Ceres, 1985. 492 p.

KOZLOWSKI, L. A. Período crítico de interferência das plantas daninhas na cultura do milho baseado na fenologia da cultura. Planta Daninha, v. 20, n. 3, p. 365-372, 2002.

MELO, A. V. Sistemas de plantio direto para milhoverde. 2004. 61 f. Dissertação. (Mestrado em Fitotecnia) Universidade Federal de Viçosa, Viçosa, MG, 2004.

PITELLI, R. A. Interferência de plantas daninhas em culturas agrícolas. Inf. Agropec., v. 11, n. 129, p. 16-27, 1985.

PROCÓPIO, S. O. et al. Absorção e utilização do nitrogênio pelas culturas da soja e do feijão e por plantas daninhas. Planta Daninha, v. 22, n. 3, p. 365-374, 2004.

SILVA, A. A.; VARGAS, L; WERLANG, R. C. Manejo de plantas daninhas na cultura do milho. In: GALVÃO, J. C. C.; MIRANDA, G. V. Tecnologias de produção do milho. Viçosa, MG: Universidade Federal de Viçosa, 2004. p. 269310 .

SOUZA NETO, J. M. Formação de pastagens de Brachiaria brizantha cv, marandu com o milho como cultura acompanhante, 1993. 58f. Dissertação (Mestrado em Fitotecnia). Escola Superior de Agricultura Luiz de Queiroz, Piracicaba, 1993.

SPADER, V.; VIDAL, R. A. Interferência de Brachiaria plantaginea sobre características agronômicas, componentes do rendimento e produtividade de grãos do milho. Planta Daninha, v. 18, n. 3, p. 465-470, 2000. 